AL-MARSHAD: JURNAL ASTRONOMI ISLAM DAN ILMU-ILMU BERKAITAN

ISSN 2442-5729 (print) || ISSN 2598-2559 (online), http://jurnal.umsu.ac.id/index.php/almarshad

DOI: https://doi.org/10.30596/jam.v4i1.1938

Published June 2018

\title{
Pemikiran Thomas Djamaluddin tentang Salat dan Puasa \\ di Daerah Dekat Kutub
}

\author{
Rizalludin \\ Universitas Islam Negeri Waslisongo Semarang \\ Email: rizalludin46@gmail.com
}

\begin{abstract}
Abstrak
With the development of science of hisab today, the time of prayer and fasting can be calculated because the movement of the Sun is relatively fixed. This only applies to areas that have normal day and night turns. However, in extreme areas with latitudes greater than $48^{\circ}$ (areas close to the poles), continuous twilight may occur namely continuous twilight and dawn light may even occur at late night so that early dawn and sunset to begin and break the fasting can not be determined. Responding to the issue, some argues that the practice of prayer is worshiped with people who fall asleep while fasting is replaced in other months. Another opinion suggests that to follow the time in the surrounding normal area or follow the areas where the sharia came down, namely Mecca and Medina. Those opinions have imperfect weaknesses in performing Ramadan because it can happen one full month of Ramadan that people can not carry out fasting and the prayer times between different regions vary due to the ever-moving circulation of the Sun. Meanwhile, Thomas Djamaluddin offers a time interpolation solution by taking into account the time before and after the extreme time so that the obligation of five-time prayers can still be held every day and fasting is held in Ramadan. However, this opinion has a weakness that the implementation of isya and subuh prayer and fasting is not appropriate to shari'ah because it is held in the light of twilight is still visible.
\end{abstract}

Keyword: Prayer, Fasting, Areas Near The Poles.

\section{A. Latar Belakang}

Salah satu syarat sah salat adalah dikerjakan sesuai dengan waktuwaktunya. Pada zaman dahulu umat Islam menentukan awal waktu salat dengan melakukan pengamatan secara langsung terhadap pergerakan semu Matahari. Hal ini akan memunculkan persoalan bagi kita ketika keadaan langit mendung, Matahari tidak 
AL-MARSHAD: JURNAL ASTRONOMI ISLAM DAN ILMU-ILMU BERKAITAN

ISSN 2442-5729 (print) || ISSN 2598-2559 (online), http://jurnal.umsu.ac.id/index.php/almarshad DOI: https://doi.org/10.30596/jam.v4i1.1938

Published June 2018

memancarkan sinarnya secara maksimal. Selain itu juga, pada waktuwaktu tertentu sinar Matahari tidak sampai pada tempat-tempat tertentu, misalnya daerah kutub. ${ }^{1}$

Menurut Susiknan Azhari, ada tiga kemungkinan kondisi Matahari di daerah kutub. Pertama, ada wilayah yang pada bulan-bulan tertentu mengalami siang selama 24 jam sehari atau sebaliknya mengalami malam selama 24 jam sehari. Kedua, ada wilayah yang pada bulan tertentu tidak mengalami hilangnya mega merah (syafaqul ahmar) sampai datangnya waktu subuh sehingga tidak bisa dibedakan antara mega merah saat magrib dan mega merah saat subuh. Ketiga, ada wilayah yang masih mengalami pergantian malam dan siang dalam satu hari, meski panjang siang sangat singkat sekali atau sebaliknya. ${ }^{2}$

Jika melihat dari tiga kemungkinan di atas, maka permasalahan yang muncul bagi umat Islam yang berada di sana adalah bukan

1 Sa'addoedin Djambek, Salat dan Puasa di Daerah Kutub, (Jakarta: Bulan Bintang, $\mathrm{tt})$., h.7.

2 Susiknan Azhari, Ilmu Falak (Perjumpaan Khazanah Islam dan Sains Modern), (Yogyakarta: Suara Muhammadiyah, cet. II, 2007), h. 70. hanya sebatas kewajiban menunaikan salat lima waktu, tetapi juga berimbas pada kapan memulai dan mengakhiri kewajiban puasa di bulan Ramadan. Oleh karena itu, para ulama berbeda pendapat dalam menyelesaikan permasalahan ini. Sebagian ulama mengatakan bahwa jadwal imsakiah Ramadan dan jadwal waktu salat fardhu lima waktu untuk kawasan dekat kutub disesuaikan dengan negeri tetangga yang panjang malamnya sedang. Sementara sebagian ulama lainnya berpendapat bahwa penentuan waktunya harus disesuaikan dengan jadwal imsakiah Ramadan yang berlaku di tanah tempat lahirnya agama Islam, yaitu tanah Hijaz (Mekkah dan Madinah). Kedua pendapat di atas berdasarkan ijtihad ulama, tidak ada nash (al-Qur'an dan hadis) yang menguatkan masalah tersebut. Jadi kedua-duanya boleh diikuti. ${ }^{3}$

\section{${ }^{3}$ H.Z.A. Syihab, Tuntunan Puasa} Praktis, (Jakarta: Bumi Aksara, 1995), h. 43. Pendapat pertama disampaikan juga oleh Wahbah az-Zuhaili, selengkapnya bisa dibaca di Fiqih Islam Wa Adillatuhu, (Damaskus: Dar al-Fikr, 2006), h.664. sementara pendapat kedua disampaikan oleh Sayyid Sabiq dalam Fiqhus Sunnah, Jilid I, (Mesir: Darul Fatah li I'lam Arabi, 1990). h. 467. 
Berbeda dengan Thomas

Djamaluddin yang berpendapat bahwa kewajiban salat dan puasa di bulan Ramadan untuk daerah kutub tetap harus dilaksanakan pada saat itu juga. Artinya, walaupun pada saat jatuhnya bulan Ramadan Matahari tidak dapat dibedakan antara terbit dan terbenam atau bahkan 24 jam siang dalam sehari atau sebaliknya, salat dan puasa tetap harus dilaksanakan. Dengan perhitungan astronomi hal itu dapat dilakukan, dimana waktu-waktu salat dan puasa diqiyaskan dengan waktu normal sebelumnya. ${ }^{4}$

Berangkat dari penjelasan di atas, perlu kiranya untuk dikaji terkait salat dan puasa bagi umat Islam yang berada di daerah kutub atau daerah-daerah pada lintang tinggi ketika bertepatan dengan waktu ektrim. Dalam makalah ini, pembahasan lebih dikhususkan terhadap pendapatnya Thomas Djamaluddin yang memberikan solusi melalui perhitungan astronomi.

${ }^{4}$ Thomas Djamaluddin, Menggagas Fiqih Astronomi (Telaah Hisab-Rukyat dan Pencarian Solusi perbedaan hari Raya), (Bandung:Kaki Langit, cet. I, 2005), h. 3334.

\section{A. Biografi Thomas Djamaluddin}

Nama aslinya adalah

Djamaluddin, ia lahir di Purwokerto, 23 Januari 1962 M. Ia adalah buah cinta dari pasangan Sumaila Hadiko, Purnawirawan TNI AD asal Gorontalo dan Duriyah asal Cirebon. Tradisi Jawa untuk mengganti nama anak yang sakitsakitan menyebabkan namanya diganti menjadi Thomas ketika umurnya sekitar 3 tahun. $^{5}$ Pada tahun 1981 T. Djamaluddin diterima tanpa tes di ITB melalui PP II (Proyek Perintis II), sejenis PMDK (Penelusuran, Minat, Dan Kemampuan). Sesuai dengan minatnya sejak duduk dibangku SMP, di ITB ia memilih jurusan Astronomi. ${ }^{6}$ Pengetahuannya tentang ilmu-ilmu keislaman, Djamaluddin banyak belajar dari lingkungan keluarganya sendiri dan diperdalam secara otodidak dari membaca buku. Lulus dari ITB (1986), ia kemudian masuk di LAPAN (Lembaga Penerbangan dan Antariksa Nasional)

\begin{tabular}{l}
\hline 5 Thomas Djamaluddin, \\
Menjelajah Keluasan Langit Menembus \\
Kedalaman Al-qur'an, (Lembang: Penerbit \\
Khazanah Intelektual, 2006), h.123. \\
6 https://tdjamaluddin.wordpress \\
$\frac{\text { com/1-t-djamaluddin- }}{\text { thomas\%20djamaluddin/ diakses pada }}$ \\
tanggal 29 Mei 2017 jam 12:54 WIB.
\end{tabular}


Bandung dengan menjadi peneliti antariksa. Pada tahun 1988-1994 ia mendapatkan kesempatan tugas belajar program S2 dan S3 ke Jepang di Department of Astronomy, Kyoto University dengan beasiswa Monbusho. Tesis master dan doktornya berkaitan dengan materi antar bintang dan pembentukan bintang dan evolusi bintang muda. Namun demikian, aplikasi Astronomi dalam bidang hisab dan rukyat terus ditekuninya. Atas permintaan teman-teman mahasiswa Muslim di Jepang dibuatlah program jadwal salat, arah kiblat, dan konversi kalender.

Ia juga pernah menjadi Kepala Unit Komputer Induk, Kepala Bidang Matahari dan Antariksa, dan Kepala Pusat Pemanfaatan Sains Atmosfer dan Iklim, LAPAN. ${ }^{7}$ Terkait dengan kegiatan penelitian, saat ini ia menjadi anggota Himpunan Astronomi Indonesia (HAI), International Astronomical Union (IAU), dan National Committee di Committee on Space Research (COSPAR), serta anggota Badan Hisab Rukyat (BHR)

7 Thomas Djamaluddin, Asronomi Memberi Solusi Penyatuan Umat, (Jakarta: LAPAN, 2011), h. ii.
Kemenag RI. Lebih dari 50 makalah ilmiah, lebih dari 100 tulisan populer, dan 5 buku tentang astronomi dan keislaman telah dipublikasikannya. ${ }^{8}$ Sampai tahun 2017 tulisan Thomas Djamaluddin 127 tentang Astronomi dan Antariksa, 141 tentang HisabRukyat, 50 tentang Sains Kebumian, 39 tentang Integrasi Sains- Qur'an dan 60 tentang Hikmah dan keilmuan lain. ${ }^{9}$

\section{B. Pemikiran}

Thomas

\section{Djamaluddin tentang Salat dan}

\section{Puasa di Daerah Dekat Kutub}

Menurut Thomas Djamaluddin, puasa pada bulan Juni atau Desember merupakan saat ekstrim bagi wilayah di lintang tinggi (daerah dekat kutub), variasi panjang hari akan sangat mencolok. Bulan Juni merupakan puasa terpanjang bagi wilayah di belahan Bumi utara, tetapi terpendek bagi wilayah di belahan bumi Selatan. Sedangkan puasa pada bulan DesemberJanuari, merupakan puasa terpendek bagi wilayah di belahan Bumi Utara, tetapi terpanjang bagi wilayah di

8 Thomas Djamaluddin, Menjelajah ..., h. 125-126.

9 https://tdjamaluddin.wordpress. com/ diakses pada tanggal 29 Mei 2017 jam 13:20 WIB. 
belahan Bumi Selatan. Pada keadaan ekstrim seperti itu, di daerah lintang tinggi bisa terjadi continuous twilight, yaitu bersambungnya cahaya senja dan cahaya fajar bahkan bisa juga terjadi malam terus sehingga awal fajar dan magrib untuk memulai dan berbuka puasa tidak bisa ditentukan. Thomas Djamaluddin, menawarkan sebuah solusi interpolasi waktu untuk memulai dan mengakhiri puasa dapat menggunakan perhitungan waktu normal setempat, yaitu sebelum dan sesudah waktu ektrim. Dalam keadaan ekstrim seperti itu waktu-waktu salat dan puasa diqiyaskan dengan waktu normal sebelumnya. Berdasarkan perhitungan astronomis, panjang puasa pada saat normal di seluruh dunia tidak lebih dari 20 jam sehingga dengan adanya waktu minimal 4 jam untuk berbuka dan bersahur, hal itu masih dalam batas kekuatan manusia ${ }^{10}$. Jadi selama tidak normal, jadwal salat termasuk waktu puasa didasarkan pada jam, tidak berdasarkan fenomena sesungguhnya.

Seiring berkembangnya ilmu falak, sekarang jadwal waktu salat

\footnotetext{
${ }^{10}$ Thomas Djamaluddin, Menggagas ..., h. 32-34.
}

sudah banyak beredar di masyarakat, bahkan ada pula jadwal waktu salat yang berlaku di suatu tempat, dapat dikonversi penggunanya dengan tempat lain hanya memperhitungkan perbedaan Bujur saja. ${ }^{11}$ Jadwal salat digunakan sebagai tanda dimulainya puasa pada waktu subuh dan Magrib untuk mengakhiri. Di dalam hadits disebutkan bahwa waktu subuh adalah sejak terbit fajar shidiq (sebenarnya) sampai terbitnya Matahari. Maka secara astronomi fajar shidiq difahami sebagai awal astronomical twilight (fajar astronomi), mulai munculnya cahaya di ufuk timur menjelang terbit matahari pada saat Matahari berada pada kira-kira 18 derajat di bawah horizon (jarak zenit $\mathrm{z}=108^{\circ}$ ). Fajar shidiq itu disebabkan oleh hamburan cahaya Matahari di atmosfer atas. Ini berbeda dengan apa yang disebut fajar kidzib (semu) - dalam istilah astronomi disebut cahaya zodiak yang disebabkan

11 Sofwan Jannah, "Urgensi Hisab dan Rukyat pasca UU No. 3 Tahun 2006", Islamic University of Indonesia: AlMawarid Jurnal Hukum Islam Vol 17 (2007), h. 116-117. 
oleh hamburan cahaya Matahari oleh debu-debu antar planet. $^{12}$

$$
\text { Penentuan waktu subuh }
$$
diperlukan untuk penentuan awal puasa. Tentang waktu awal shaum disebutkan dalam Al-Quran,

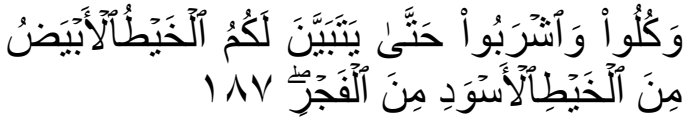

Artinya: "makan minumlah hingga terang bagimu benang putih dari benang hitam, yaitu fajar" (QS. Albaqarah:187) ${ }^{13}$

Awal waktu subuh disebutkan di dalam hadis adalah sejak terbit fajar shadiq $^{14}$ (sebenarnya) sampai terbitnya Matahari. Dalam Al-Qur'an secara tak langsung disebutkan sejak meredupnya bintang-bintang (QS.50:40). ${ }^{15}$ Awal waktu magrib berarti saat terbenamnya

${ }^{12}$ Thomas Djamaluddin, Menggagas Fiqih Astronomi, (Bandung: Kaki Langit, 2005). h. 138.

13 Departemen Agama Republik Indonesia, Al-Qur'an Al-Qur'an dan Terjemahnya, (Jakarta: Sygma Creative Media Crop, 2009), h. 29

14 Awal fajar shadiq yang tampak terang terkadang berwarna putih, merah, putih kemerahan, atau bahkan ada warna birunya. Lihat Moh. Afif Amrullah, "Penentuan Awal Waktu Shalat Subuh Menurut Kementrian Agama dan Aliran Salafi", Jurnal Hukum dan Syariah JURISDICTIE Vol 2, No 2 Desember 2011, h. 129.
15 Thomas
Djamaluddin,
Menggagas..., h. 138.

Matahari. Matahari terbit atau berbenam didefinisikan secara astronomi bila jarak zenith $\mathrm{z}=90^{\circ} 50^{\prime}$ (the Astronomical almanac) atau $\mathrm{z}=91^{\circ}$ bila memasukkan koreksi kerendahan ufuk akibat ketinggian pengamat 30 meter dari permukaan tanah. Untuk penentuan waktu salat magrib, saat Matahari terbenam biasanya ditambah 2 menit karena ada larangan melakukan salat tepat saat Matahari terbit, terbenam, atau kulminasi atas. Waktu isya ditandai dengan mulai memudarnya cahaya merah di ufuk barat, yaitu tanda masuknya gelap malam. Dalam astronomi itu dikenal sebagai akhir senja astronomi (astronomical twilight) bila jarak zenit Matahari $\left.\mathrm{z}=108^{\circ}\right)^{16}$.

Dengan bantuan jadwal waktu salat inilah penentuan puasa di daerah ekstrim dapat dilakukan, caranya adalah dengan menginterpolasi untuk waktu yang tidak tercantum, untuk memulai dan mengakhiri puasa dapat menggunakan perhitungan waktu normal setempat, yaitu sebelum dan sesudah waktu ektrim.

Interpolasi waktu salat di daerah yang tidak teridentifikasi waktu

\footnotetext{
${ }^{16}$ Thomas Djamaluddin, Menggagas..., h. 139.
} 
salatnya dengan waktu sebelum dan sesudah ekstrem dengan menggunakan rumus:

$$
\mathrm{A}+(\mathrm{B}-\mathrm{A}) \times \mathrm{K} \div \mathrm{I}
$$

\section{Keterangan:}

A : Jadwal salat sebelum ekstrim

B : Jadwal salat setelah ekstrem

$\mathrm{K}$ : Tambah waktu /data yang dicari (Jumlah hari yang tidak normal sampai dengan hari yang dimaksud)

I : Interval dari A hingga B.

Thomas Djamaluddin berijtihad berdasar pada hadis Nabi digunakan dengan jalan qiyas yaitu hadis tentang turunnya Dajjal yang diriwayatkan oleh imam Muslim, yaitu: ${ }^{17}$

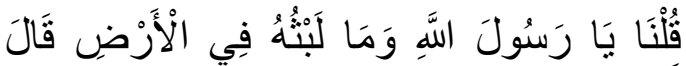

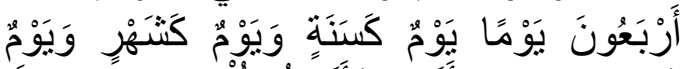

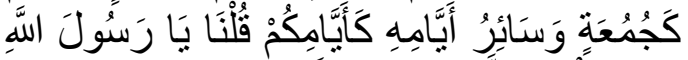

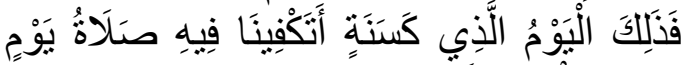

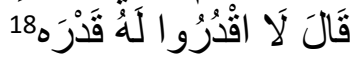

Artinya: "Kami bertanya, wahai Rasulullah berapa hari dia (Dajjal) tinggal di Bumi? Rasulullah saw. menjawab, empat puluh hari. Satu hari seperti setahun, satu hari seperti sebulan, satu hari seperti sepekan, dan

17 Thomas Djamaluddin,

Menggagas..., h. 33 .

18 Al Imam Yahya bin Syarif anNawawi ad-Dimsyiqy asy-Syafi'i, Shahih Muslim bi Syarhi an-Nawawi, Jus 17, Beirut; Dar al-Dekat kutub al-'Alamiyyah, tt. hlm. 50-57. hari-hari lainnya seperti hari-hari kalian. Kami bertanya lagi, wahai Rasulullah tentang satu hari seperti setahun itu, apakah cukup bagi kami salat sehari? Beliau menjawab, tidak, tapi perkirakanlah kadarnya." (HR. Muslim).

Thomas Djamaluddin menjelaskan "Untuk daerah dengan lintang lebih dari 48 derajat pada musim panas senja dan fajar bersambung (continuous twilight). ${ }^{19}$.

Tabel 01. Daftar nama beberapa kota berlintang lebih dari $48^{\circ}$

\begin{tabular}{|c|c|c|c|}
\hline No. & Nama Kota & Lintang & Bujur \\
\hline 1 & Brussel-Belgium & 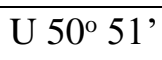 & $04^{\circ} 21^{\prime} \mathrm{T}$ \\
\hline 2 & $\begin{array}{l}\text { London- United } \\
\text { Kingdom }\end{array}$ & $\mathrm{U} 51^{\circ} 30^{\prime}$ & $00^{\circ} 05^{\prime} \mathrm{B}$ \\
\hline 3 & Rotterdam-Netherand & $\mathrm{U} 51^{\circ} 55^{\prime}$ & $04^{\circ} 30^{\prime} \mathrm{T}$ \\
\hline 4 & $\begin{array}{l}\text { 'S-Gravanbage- } \\
\text { Netherland }\end{array}$ & $\mathrm{U} 52^{\circ} 05^{\prime}$ & $04^{\circ} 18^{\prime} \mathrm{T}$ \\
\hline 5 & $\begin{array}{l}\text { Amsterdam- } \\
\text { Netherland }\end{array}$ & $\mathrm{U} 52^{\circ} 21^{\prime}$ & $04^{\circ} 55^{\prime} \mathrm{T}$ \\
\hline 6 & Berlin- Germany & $\mathrm{U} 52^{\circ} 31^{\prime}$ & $13^{\circ} 23^{\prime} \mathrm{T}$ \\
\hline 7 & $\begin{array}{l}\text { Groningen- } \\
\text { Netherland }\end{array}$ & $\mathrm{U} 53^{\circ} 13^{\prime}$ & $06^{\circ} 34^{\prime} \mathrm{T}$ \\
\hline 8 & Dublin- Ireland & ${\mathrm{U} 53^{\circ} 21^{\prime}}^{\prime}$ & $06^{\circ} 15^{\prime} \mathrm{B}$ \\
\hline 9 & Hamburg-Germany & $\mathrm{U}^{2} 3^{\circ} 33^{\prime}$ & $09^{\circ} 58^{\prime} \mathrm{T}$ \\
\hline 10 & $\begin{array}{l}\text { Liverpool-United } \\
\text { Kingdom }\end{array}$ & U $53^{\circ} 33^{\prime}$ & $03^{\circ} 00^{\prime} \mathrm{B}$ \\
\hline
\end{tabular}

19 Thomas Djamaluddin, Menggagas Fiqih Astronomi, (Bandung: Kaki Langit, 2005), h. 138-139. 
AL-MARSHAD: JURNAL ASTRONOMI ISLAM DAN ILMU-ILMU BERKAITAN

ISSN 2442-5729 (print) || ISSN 2598-2559 (online), http://jurnal.umsu.ac.id/index.php/almarshad DOI: https://doi.org/10.30596/jam.v4i1.1938

Published June 2018

\begin{tabular}{|c|c|c|c|}
\hline 11 & $\begin{array}{l}\text { Moskow-Rusian } \\
\text { Federation }\end{array}$ & U $55^{\circ} 45^{\prime}$ & $37^{\circ} 36^{\prime} \mathrm{T}$ \\
\hline 12 & $\begin{array}{l}\text { Edinburg-United } \\
\text { Kingdom }\end{array}$ & $\mathrm{U} 55^{\circ} 57^{\prime}$ & $03^{\circ} 11^{\prime} \mathrm{B}$ \\
\hline 13 & Schotlandia & $\mathrm{U}^{\circ} 46^{\circ}$ & $04^{\circ} 30^{\prime} \mathrm{B}$ \\
\hline 14 & Stockholm-Swedan & $\mathrm{U}^{2} 9^{\circ} 20^{\prime}$ & $18^{\circ} 00^{\prime} \mathrm{T}$ \\
\hline 15 & Magadan & $\mathrm{U}^{5} 9^{\circ} 40^{\prime}$ & $151^{\circ} 00^{\prime} \mathrm{T}$ \\
\hline 16 & Oslo-Norwegia & $\mathrm{U}^{\circ} 9^{\circ} 57^{\prime}$ & $10^{\circ} 45^{\prime} \mathrm{T}$ \\
\hline 17 & Helsinki-Finlandia & $\mathrm{U}^{\circ} 60^{\circ} 13^{\prime}$ & $24^{\circ} 58^{\prime} \mathrm{T}$ \\
\hline 18 & Leksand & $\mathrm{U} 60^{\circ} 45^{\prime}$ & $15^{\circ} 05^{\prime} \mathrm{T}$ \\
\hline 19 & Lahti & $\mathrm{U} 60^{\circ} 55^{\prime}$ & $25^{\circ} 45^{\prime} \mathrm{T}$ \\
\hline 20 & Pori & $\mathrm{U} 61^{\circ} 29^{\prime}$ & $21^{\circ} 32^{\prime} \mathrm{T}$ \\
\hline 21 & Sundsvall & $\mathrm{U} 62^{\circ} 21^{\prime}$ & $17^{\circ} 12^{\prime} \mathrm{T}$ \\
\hline 22 & Trondheim & $\mathrm{U} 63^{\circ} 25^{\prime}$ & $10^{\circ} 20^{\prime} \mathrm{T}$ \\
\hline 23 & Kayaami & $\mathrm{U} 64^{\circ} 15^{\prime}$ & $27^{\circ} 42^{\prime} \mathrm{T}$ \\
\hline 24 & Kemi & $\mathrm{U} 65^{\circ} 45^{\prime}$ & $24^{\circ} 50^{\prime} \mathrm{T}$ \\
\hline 25 & Haparanda & $\mathrm{U} 65^{\circ} 49^{\prime}$ & $24^{\circ} 00^{\prime} \mathrm{T}$ \\
\hline 26 & Kemiyarvi & $\mathrm{U}^{6} 6^{\circ} 30^{\prime}$ & $25^{\circ} 45^{\prime} \mathrm{T}$ \\
\hline 26 & Bedo & $\mathrm{U} 67^{\circ} 16^{\prime}$ & $14^{\circ} 22^{\prime} \mathrm{T}$ \\
\hline 27 & Kiruna & $\mathrm{U}^{6} 67^{\circ} 50^{\prime}$ & $20^{\circ} 20^{\prime} \mathrm{T}$ \\
\hline 28 & Kirkenes & $\mathrm{U} 69^{\circ} 45^{\prime}$ & $30^{\circ} 00^{\prime} \mathrm{T}$ \\
\hline 29 & Jan Mayen & $\mathrm{U}^{\circ} 70^{\circ} 40^{\prime}$ & $08^{\circ} 00^{\prime} \mathrm{B}$ \\
\hline 30 & Reykjavik- Iceland & $\mathrm{U} 64^{\circ} 05^{\prime}$ & $21^{\circ} 50^{\prime} \mathrm{B}$ \\
\hline 31 & Punta Arenas- Chile & $\mathrm{S} 53^{\circ} 20^{\prime}$ & $71^{\circ} 00 \mathrm{~B}$ \\
\hline
\end{tabular}

mengakhiri sahur pada waktu Subuh dan berbuka pada waktu Magrib.

Kasus ekstrim seperti itu untungnya tidak terjadi selamanya. Adanya perbedaan panjang tahun kamariyah (kalender Bulan) dan tahun syamsiah (kalender Matahari) menyebabkan awal Ramadan dan hari raya selalu bergeser sekitar 11 hari lebih awal. Sehingga bila Ramadan jatuh pada sekitar bulan Maret dan September, semuanya berjalan normal lagi, seperti halnya puasa di daerah ekuator. Pada sekitar bulan Maret dan September, panjang siang dan malam hampir sama di seluruh dunia. ${ }^{20}$

\section{Analisis terhadap pemikiran Thomas Djamaluddin tentang Salat dan Puasa di daerah dekat Kutub}

Salat dan puasa di daerah dekat kutub menjadi masalah karena tidak ada satupun keterangan al-Qur'an dan hadis Nabi yang menjelaskan tata cara salat

${ }^{20}$ Thomas Djamaluddin, Menggagas

Lintang lebih dari 48 derajat adalah batas untuk mengidentifikasi adanya waktu salat yang digunakan Thomas Djamaluddin sebagai batas 
dan berpuasa di daerah sekitar kutub ${ }^{21}$. Mengenai puasa Ramadan hanya ada penjelasan bahwa awal Ramadan dimulai ketika hilal terlihat, puasa dimulai ketika fajar terbit, dan berbuka ketika ghurub ${ }^{22}$. Bisa dipahami alasan mengapa al-Qur'an dan hadis tidak pernah menyinggung perkara di atas adalah disebabkan wahyu diturunkan di daerah yang notabane tergolong dekat dengan khatulistiwa, di mana perjalanan dan pergantian waktu berjalan secara normal.

Pertanyaannya adalah apakah salat lima waktu itu sebuah kewajiban karena datangnya waktu salat, atau salat lima waktu itu kewajiban mutlak yang harus dilaksanakan pada waktu-waktu yang telah ditentukan. Puasa pada bulan Ramadan termasuk dalam rukun Islam yang lima, ibadah tersebut juga ditentukan batasan waktunya, yaitu; Pertama, puasa dilaksanakan pada bulan Ramadan ketika hilal terlihat, dan Kedua, hari puasa dimulai ketika fajar terbit dan berakhir saat Matahari terbenam.

${ }^{21}$ Mahmud Syaltout, Fatwa-Fatwa, Jilid I, Terj. Fatawa, (Jakarta; Bulan Bintang, 1972), h. 165.

${ }^{22}$ Kementerian Agama, Almanak Hisab Rukyat, (Jakarta; Kementrian Agama, 2010), h. 26.
Majelis Fatwa al-Azhar AsySyarif berpendapat, sebagaimana dikutip Susiknan Azhari dan Salamet Hambali, bahwa pada daerah-daerah yang tidak teratur masa siang dan malamnya, dilakukan dengan cara menyesuaikan/menyamakan waktunya dengan daerah dimana batas waktu siang dan malam setiap tahunnya tidak jauh berbeda (teratur). Misalnya mengikuti Saudi Arabia. Daerah yang sama sekali tidak diketahui waktu fajar dan Magribnya seperti daerah kutub (utara dan selatan), maka salatnya menyesuaikan dengan daerah lain. ${ }^{23}$

Sayyid Sabiq dalam buku Fikih Sunnah, mengatakan bahwa apabila suatu tempat di daerah dekat kutub, bulan Ramadannya jatuh pada salah satu bulan yang fajarnya tidak terbit maka puasa tetap dilaksanakan dengan cara mengikuti negara tempat turunnya syariah yaitu Mekkah dan Madinah' ${ }^{24}$.

Bahkan ada yang berpendapat bahwa tidak ada kewajiban puasa apabila suatu tempat di daerah dekat kutub fajar tidak terbit maka orang tidak

${ }^{23}$ Susiknan Azhari, Ilmu Falak ..., h. 72. Dan, Slamet Hambali, Ilmu Falak 1 ..., h. 138.

${ }^{24}$ Sayyid Sabiq, Fiqhus Sunnah, Jilid I, (Mesir: Darul Fatah li I'lam Arabi, 1990), h. 467 
dapat melakukan puasa Ramadan, karena salah satu syarat untuk melakukan puasa, yaitu terbitnya fajar, tidak dapat dipenuhi. Dalam hal demikian, jumlah hari puasa yang tertinggal itu harus diqadha pada bulanbulan berikutnya ${ }^{25}$. Adapun untuk waktu salatnya dapat diqiyaskan dengan orang yang tertidur atau pingsan. ${ }^{26}$ Lebih tegas lagi K. Noor Ahmad S.S. berpendapat, tidak ada kewajiban salat bagi mereka yang tinggal di daerah kutub pada saat waktu salat tidak ditemukan karena kewajiban melaksanakan salat itu disebabkan oleh fenomena yang terkait dengan perubahan posisi harian Matahari akibat pergerakan semu hariannya. Berdasarkan fenomena tersebutlah kewajiban salat disyari'atkan. ${ }^{27}$

Sementara Thomas Djamaluddin berpendapat bahwa apabila tidak terjadi fajar terbit atau Matahari tidak terbenam

${ }^{25}$ Saadoeddin Djambek, Shalat dan Puasa di Daerah kutub, (Jakarta: Bulan Bintang, 1974), h. 18. 17.

${ }^{26}$ Saadoeddin Djambek, Shalat..., h.

27 Noor Ahmad SS, Salat di daerah Kutub dalam wawancara Jayusman, "Pemikiran Ilmu Falak Kyai Noor Ahmad SS", Disertasi Program Pascasarjana IAIN Walisongo Semarang: Perpustakaan Walisongo, 2013. di salah satu daerah dekat kutub maka puasa Ramadan tetap bisa dilakukan. Mengingat puasa Ramadan adalah wajib dengan perhitungan jam yang dihitung dengan memperkirakan waktu normal sebelum dan sesudah ekstrim. Hal ini dipandang sebagai suatu langkah yang tidak memberatkan ${ }^{28}$.

Semua pendapat di atas sifatnya opsional. Artinya, umat Islam yang berada di daerah-daerah yang berlintang tinggi bebas memilih pendapatpendapat para ulama dan ahli untuk dijadikan pedoman, tidak ada satupun yang mengikat. Namun demikian, penulis lebih setuju dengan pendapat Thomas Djamaluddin karena dalam perhitungan waktu salat yang dihasilkan antara hari ini dengan kemarin serta lusa selisih yang dihasilkan tidak jauh berbeda bahkan bisa jadi sama. Menurut penulis, umat Islam di daerah dekat kutub tersebut bisa menggunakan waktu setempat. Artinya, untuk puasa tidak perlu menggantinya pada saat terbit fajar dan terbenam Matahari dapat dipastikan (waktu normal). Mereka cukup melakukan interpolasi

${ }^{28}$ Thomas Djamaluddin, Menggagas ..., h. 33-34. 
AL-MARSHAD: JURNAL ASTRONOMI ISLAM DAN ILMU-ILMU BERKAITAN

ISSN 2442-5729 (print) || ISSN 2598-2559 (online), http://jurnal.umsu.ac.id/index.php/almarshad DOI: https://doi.org/10.30596/jam.v4i1.1938

Published June 2018

perhitungan saat waktu normal sebelum dan sesudah ektrim.

Di bawah ini akan dipaparkan contoh perhitungan waktu salat daerah yang memiliki waktu normal,

Tabel 02. Perhitungan waktu salat Semarang akhir Mei dan awal Juni 2018 tanpa pembulatan dan ihtiyat

\begin{tabular}{|c|c|c|c|c|c|c|}
\hline Tanggal & Subuh & Terbit & Zuhur & Asar & Magrib & Isa \\
\hline $29 \mathrm{Mei}$ & $4: 23: 34,24$ & $5: 43: 18,04$ & $11: 35: 46$ & $14: 57: 23,33$ & $17: 28: 13,96$ & $18: 39: 21,47$ \\
\hline $30 \mathrm{Mei}$ & $4: 23: 43,22$ & $5: 43: 32$ & $11: 35: 55$ & $14: 57: 31,03$ & $17: 28: 18$ & $18: 39: 29,95$ \\
\hline $31 \mathrm{Mei}$ & $4: 23: 51,17$ & $5: 43: 48$ & 11:36:03 & $14: 57: 37,71$ & $17: 28: 21,24$ & $18: 39: 37,47$ \\
\hline 1 Juni & $4: 24: 00,09$ & $5: 44: 02$ & 11:36:12 & $14: 57: 45,39$ & $17: 28: 25,69$ & $18: 39: 46,04$ \\
\hline
\end{tabular}

Dari tabel di atas, semua waktu salat dapat ditemukan karena Semarang merupakan daerah lintang rendah dan memiliki waktu normal, yaitu Matahari selalu terbit dan terbenam. Namun, untuk pembuktian interpolasi, maka asumsikan pada tabel tersebut bahwa tanggal 29 Mei adalah waktu normal sebelum ektrim dan tanggal 1 Juni adalah waktu normal sesudah ektrim, sedangkan tanggal 30 dan 31 Mei adalah waktu ektrim atau tidak normal.

Gunakan rumus interpolasi:

$\mathrm{A}+(\mathrm{B}-\mathrm{A}) \times \mathrm{K} \div \mathrm{I}$

A : Jadwal salat sebelum ekstrim

B : Jadwal salat setelah ekstrem

K : Tambah waktu /data yang dicari (Jumlah hari yang tidak normal dimaksudkan agar mempermudah dalam pembuktiaan. Misalnya Semarang dengan data Lintang Selatan $7^{\circ}$ dan Bujur Timur $110^{\circ} 24^{\prime}$. sampai dengan hari yang dimaksud)

I : Interval dari A hingga B.

$30 \mathrm{Mei}=\mathrm{A}+(\mathrm{B}-\mathrm{A}) \times \mathrm{K} \div \mathrm{I}$

$=4: 23: 34,24+(4: 24: 00,09-4: 23: 34,24)$

$\mathrm{x} 1 \div 3$

$=4: 23: 42,86$ untuk waktu Subuh

$31 \mathrm{Mei}=\mathrm{A}+(\mathrm{B}-\mathrm{A}) \times \mathrm{K} \div \mathrm{I}$

$=4: 23: 34,24+(4: 24: 00,09-4: 23: 34,24)$

x $2 \div 3$

$=4: 23: 51,47$ untuk waktu Subuh

Perhitungan di atas ini, hanya sebatas contoh pembuktian bahwa hasil perhitungan waktu salat dalam jarak hari yang berdekatan memiliki selisih yang kecil. Dan terbukti bahwa hasil perhitungan menggunakan interpolasi dengan perhitungan menggunakan rumus waktu salat sebenarnya tidak ada selisih. Adapun selisih 0,36 detik dan 
0,3 detik tersebut bisa dianggap tidak ada, karena nilainya yang sangat kecil serta jika dilakukan pembulatan menghasilkan nilai yang sama. Menurut penulis, ini adalah solusi bagi daerahdaerah yang berlintang tinggi pada saat waktu ektrim untuk menunaikan kewajiban salat dan puasa, yaitu cukup dengan membuat jadwal salat, dimana waktu awal subuh sebagai dimulainya puasa dan awal magrib berakhirnya puasa. Pada tahun 2018, 1 Ramadan $1439 \mathrm{H}$ bertepatan dengan 17 Mei 2018, dimana pada bulan tersebut di daerahdaerah lintang tinggi adalah waktu ektrim terjadi continuous twilight, yaitu bersambungnya cahaya senja dan cahaya fajar. Akibatnya awal fajar tidak bisa ditentukan dan ini berarti sulit memastikan memulai puasanya. Oleh karena itu, dari contoh sebelumnya di atas, kita dapat menerapkan pada daerah yang berlintang tinggi misalnya Brussel-Belgium, dengan data Lintang Utara $50^{\circ} 51^{\prime}$ dan Bujur Timur 04 $21^{\circ}$.

Tabel 03. Perhitungan waktu salat Brussel-Belgium pada saat ektrim 2018

\begin{tabular}{|c|c|c|c|c|c|c|}
\hline Tanggal & Subuh & Terbit & Zuhur & Asar & Magrib & Isa \\
\hline 19 Mei & $00: 10: 27$ & $03: 47: 44$ & $11: 40: 05$ & $15: 52: 21$ & $19: 30: 27$ & $22: 36: 22$ \\
\hline $20 \mathrm{Mei}$ & $\mathrm{xxxxxx}$ & $03: 46: 27$ & $11: 40: 09$ & $15: 52: 54$ & $19: 31: 50$ & $22: 41: 32$ \\
\hline 25 Mei & $\mathrm{xxxxxx}$ & $03: 40: 38$ & $11: 40: 33$ & $15: 55: 32$ & $19: 38: 28$ & $23: 17: 41$ \\
\hline 26 Mei & $\mathrm{xxxxxx}$ & $03: 39: 36$ & $11: 40: 39$ & $15: 56: 02$ & $19: 39: 43$ & Xxxxxx \\
\hline 17 Juli & xxxxxx & $03: 48: 45$ & $11: 49: 47$ & $16: 05: 09$ & $19: 48: 49$ & Xxxxxx \\
\hline 18 Juli & xxxxxx & $03: 49: 58$ & $11: 49: 51$ & $16: 04: 50$ & $19: 47: 45$ & $23: 26: 46$ \\
\hline 22 Juli & xxxxxx & $03: 55: 04$ & $11: 50: 05$ & $16: 03: 19$ & $19: 43: 05$ & $22: 56: 58$ \\
\hline 23 Juli & $00: 08: 11$ & $03: 56: 24$ & $11: 50: 07$ & $16: 02: 52$ & $19: 41: 49$ & $22: 51: 34$ \\
\hline
\end{tabular}

Dari tabel di atas, waktu normal sebelum ektrim adalah tanggal 19 Mei. Selanjutnya tanggal $20-25$ Mei adalah hari yang tidak mengalami terbit fajar, sedangkan tanggal 26 Mei - 17 Juli adalah terjadi continuous twilight sehingga subuh dan Isa tidak dapat terdefinisikan. Kemudian tanggal 18 22 Juli kembali lagi dimana fajar tidak terbit.

Jika melihat keadaan alam di Brussel-Belgium tersebut, maka puasa 
hanya dapat dilaksanakan 3 hari, yaitu tanggal 17-19 Mei 2018 karena batasan waktu puasa menurut Q.S. 2: 187 dimulai pada awal fajar dan diakhiri pada (awal) malam (atau magrib). Oleh karena itu, masyarakat Muslim BrusselBelgium dapat menggunakan pemikiran Thomas Djamaluddin sebagai solusi agar dapat melaksanakan puasa tepat di bulan Ramadan 1439 H.

Dalam perhitungan di bawah ini secara singkat akan dilakukan interpolasi untuk mencari kapan memulai dan mengakhiri puasa bagi umat Islam Brussel-Belgium.

Mencari waktu subuh sebagai tanda dimulainya puasa.

$$
\begin{aligned}
& 20 \mathrm{Mei}=\mathrm{A}+(\mathrm{B}-\mathrm{A}) \text { x } \mathrm{K} \div \mathrm{I} \\
& =00: 10: 27+(00: 08: 11- \\
& 00: 10: 27) \times 1 \div 65 \\
& =00: 10: 24,91 \quad \text { (Waktu }
\end{aligned}
$$

Subuh)

$$
\begin{aligned}
21 \mathrm{Mei} & =\mathrm{A}+(\mathrm{B}-\mathrm{A}) \times \mathrm{K} \div \mathrm{I} \\
& =00: 10: 27+(00: 08: 11-
\end{aligned}
$$$$
00: 10: 27) \times 2 \div 65
$$

$$
=00: 10: 22,82 \quad(\text { Waktu }
$$

Subuh)

$$
\begin{aligned}
& 15 \text { Juni }=A+(B-A) \times K \div I \\
& =00: 10: 27+(00: 08: 11- \\
& 00: 10: 27) \text { x } 27 \div 65
\end{aligned}
$$

$$
=00: 09: 30,51 \quad(\text { Waktu }
$$

Subuh akhir Ramadhan)

Dari perhitungan di atas, dapat diketahui bahwa lama puasa untuk daerah Brussel-Belgium pada bulan Ramadan 1439 H adalah sekitar 19 jam 20 menit, sehingga mereka memiliki waktu untuk melaksanakan salat terawih dan sahur sekitar 4 jam 40 menit. Pendapat Thomas Djamaluddin ini dari aspek perhitungan, konsep interpolasi yang ditawarkan sudah terbukti dapat dijadikan patokan dalam memulai dan mengakhiri puasa serta menunaikan salat lima waktu pada saat ektrim di daerah lintang tinggi (dekat kutub).

Dari aspek lain, yaitu hadis nabi di atas tentang turunnya Dajjal pun dapat dipahami bahwa hadis tersebut secara implisit berbicara masalah salat lima waktu, dimana ketika Dajjal turun peredaran waktu tidak berjalan normal. Satu hari bisa menjadi seperti setahun, bisa seperti sebulan, dan bisa seperti sepekan. Maksudnya, bisa jadi dalam sehari pada masa itu hanya mengalami siang terus menerus, bisa pula malam terus menerus, atau bisa juga ditafsirkan waktu tetap berjalan normal, cuma 
karena beratnya fitnah Dajjal membuat waktu seakan berputar sangat lambat. Dalam kondisi demikian, Nabi memerintahkan agar perlaksanaan ibadat salat tetap dilakukan seperti pada hari normal. ${ }^{29}$

Dari hadis tersebut, dapat dipahami qiyas yang digunakan Thomas Djamaluddin yaitu:

a. Ashal (Pangkal) yang menjadi ukuran atau (musyabbah bih= tempat menyerupakan) yaitu kewajiban salat. Dajjal turun peredaran waktu tidak berjalan normal dengan memperkirakannya.

b. Far'un (cabang) yang diukur (musyabbah $=$ yang diserupakan $)$ adalah salat di daerah dekat kutub yang mengalami continuous twilight. Thomas menggunakan waktu Magrib untuk berbuka dan waktu Subuh untuk mengakhiri sahur dalam puasa.

c. 'Illat yaitu sifat yang menghubungkan pangkal dan cabang adalah masalah salat lima waktu dengan peredaran waktu tidak berjalan normal. Satu hari

29 T.M. Hasbi Ash Shiddieqy, Pedoman Puasa, (Jakarta: Bulan Bintang, 1954), h. 372. bisa menjadi seperti setahun, bisa seperti sebulan, dan bisa seperti sepekan. Maksudnya, dalam pembahasan ini keadaan di daerah dekat kutub yang dalam sehari bahkan berbulan-bulan hanya mengalami siang terus menerus, bisa pula malam terus menerus.

d. Hukum yang ditetapkan pada far' $i$ sesudah tetap pada ashal adalah salat tetap wajib dilakukan meskipun mengalami siang terus menerus dan malam terus menerus dengan memperkirakannya yakni dengan mengikuti waktu normal setempat, sebelum dan sesudah waktu ekstrim. Penentuaan waktu salat yang pada penentuan puasa di daerah dekat kutub waktu Magrib sebagai waktu berbuka dan Subuh sebagai waktu mengakhiri sahur tidak berdasarkan fenomena sesungguhnya melainkan berpatokan pada jam.

Tawaran solusi interpolasi waktu tersebut secara perhitungan terbukti akurat. Tetapi ada beberapa hal yang perlu diperhatikan dalam mengaplikasikan solisi tersebut, diantaranya:

1. Konversi jadwal untuk daerah lain 
Sering ditemukan dalam jadwal waktu salat terdapat selisih waktu untuk daerah atau kota lain agar dapat dipergunakan untuk daerah atau kota tersebut. Sebetulnya melakukan koreksi dengan hanya menambahkan selisih waktu tersebut tidaklah tepat sebab selisih waktu yang tercantum adalah hanya berpedoman pada perbedaan Bujur kota yang bersangkutan dengan kota yang dijadikan pedoman. Dalam hal ini, pengaplikasian interpolasi waktu untuk daerah dekat kutub pada saat ektrim dimana waktu salat secara perhitungan biasa tidak dapat ditemukan waktu subuh dan atau waktu isya, maka harus diperhatikan bahwa pembuatan jadwal waktu salat tersebut hanya berlaku untuk daerah atau kota yang data koordinat Lintang dan Bujur tempatnya diperhitungkan. Mengingat daerah-daerah ektrim tersebut memiliki lintang yang tinggi, maka tidak cukup melakukan konversi waktu hanya berpedoman pada selisih Bujur saja, harus memperhitungkan Lintang dan Deklinasi Matahari.
Oleh karena itu, alangkah lebih baiknya untuk masing-masing kota pada suatu negara yang berdekatan dengan kutub melakukan perhitungan waktu salat sendirisendiri sehingga jadwal waktu salat yang terbentuk sesuai.

2. Konsistensi perhitungan sebagai solusi peribadatan

Ibadah puasa dimulai dari penentuan awal bulan kamariah. Sampai saat ini, perdebatan penentuan awal bulan kamariah antara menggunakan hisab (perhitungan) atau dengan rukyat (observasi) masih belum selesai. Interpolasi waktu merupakan solusi yang berbentuk perhitungan (hisab). Oleh karena itu, pada saat terjadi bersambungnya cahaya senja dengan fajar (continuous twilight), orang Muslim kebingungan untuk mengawali puasa serta kapan harus melaksanakan salat Subuh dan Isya. Observasi secara langsung tentunya yang didapatkan hanya 3 waktu salat, yaitu Zuhur, Asar dan Magrib sedangkan puasa tidak didapati fajar shidiq. Pada keadaan tersebut, hisab menjadi solusinya, yaitu 
AL-MARSHAD: JURNAL ASTRONOMI ISLAM DAN ILMU-ILMU BERKAITAN

ISSN 2442-5729 (print) || ISSN 2598-2559 (online), http://jurnal.umsu.ac.id/index.php/almarshad DOI: https://doi.org/10.30596/jam.v4i1.1938

Published June 2018

dengan disusunnya jadwal waktu salat dengan bantuan teori interpolasi waktu bagi waktu yang tidak dapat ditentukan sehingga salat dan puasa dapat dilaksanakan pada hari itu tanpa harus mengganti pada hari lain ketika siang dan malam kembali normal. Jika solusi interpolasi waktu adalah pilihan yang diambil, maka dalam menentukan awal bulan kamariahkhususnya Ramadhan, Syawal dan Zulhijjah harus menggunakan hisab sehingga terdapat konsistensi perhitungan sebagai solusi dalam melaksanakan ibadah.

3. Keadaan alam

Perhitungan awal waktu salat pada hakekatnya adalah perhitungan untuk menentukan peredaran Matahari mencapai kedudukan atau ketinggian tertentu sesuai dengan awal waktu shalat. ${ }^{30}$ Oleh karena pada daerah ektrim terjadi bersambungnya cahaya senja dengan fajar (continuous twilight), maka perhitungan untuk awal

${ }^{30}$ Ahmad Khoiri, "Penentuan Awal Waktu Shalat Fardhu dengan Peredaran Matahari", JURNAL SPEKTRA Vol 3, No 1 (2017): Kajian Sains, Sains Terapan page. h. 44 . waktu Subuh dan atau Isya tidak dapat ditentukan sebab rumus yang digunakan berdasarkan pada peredaran Matahari sebenarnya. Akan terasa aneh ketika seorang Muslim melaksanakan salat Isya sedangkan cahaya Matahari senja masih nampak, begitu juga saat mengerjakan salat Subuh dimana seharusnya keadaan alam gelap justru cahaya Matahari masih nampak. Dalam mengaplikasikan tawaran interpolasi waktu tersebut, perlu adanya kesepakatan oleh umat Islam di wilayah ektrim tersebut sehingga jadwal waktu salat dapat disusun tanpa mempermasalahkan keadaan alam yang tidak sesuai dengan peredaran Matahari untuk waktu salat Subuh dan atau Isya.

\section{Kesimpulan}

Thomas Djamaluddin memiliki konsep mengenai salat dan puasa di daerah dekat kutub yang dituangkan dalam bukunya Menggagas Fiqh Astronomi, bahwa apabila bulan Ramadan jatuh pada waktu ekstrim, maka untuk memulai dan mengakhiri puasa dapat menggunakan perhitungan 
waktu normal setempat, yaitu sebelum dan sesudah waktu ektrim. Dalam keadaan ekstrim seperti itu waktuwaktu salat dan puasa diqiyaskan dengan waktu normal sebelumnya. Berdasarkan perhitungan astronomis, panjang puasa pada saat normal di seluruh dunia tidak lebih dari 20 jam sehingga dengan adanya waktu minimal 4 jam untuk berbuka dan bersahur, hal itu masih dalam batas kekuatan manusia. Jadi selama tidak normal, jadwal salat termasuk waktu puasa didasarkan pada jam, tidak berdasarkan fenomena sesungguhnya. Hal ini bertentangan dengan dalil-dalil alqur'an dan Hadis yang menjelaskan tentang waktu-waktu salat, tetapi jika memaksakan untuk melaksanakan salat sesuai dengan fenomena edaran Matahari maka bagi daerah-daerah lintang tinggi yang mengalami bersambungnya cahaya senja dengan fajar (continuous twilight) hanya ada 3 waktu salat, yaitu Zuhur, Asar dan Magrib. Selain waktu salat, juga berpengaruh pada pelaksanaan puasa dimana seorang Muslim harus berhenti makan dan minum untuk memulai puasa padahal cahaya senja masih terlihat. Sementara itu, kewajiban seorang Muslim untuk melaksanakan salat adalah 5 waktu dan kewajiban berpuasa adalah di bulan Ramadhan. Oleh karena itu, agar kewajiban salat 5 waktu dan puasa Ramadhan tetap dilaksanakan tanpa harus mengganti pada bulan lain ketika keadaan siang dan malam normal, maka pembuatan jadwal waktu salat dengan bantuan interpolasi waktu bisa dijadikan sebagai solusi

Dalam prakteknya, tidak cukup satu jadwal waktu salat di suatu daerah ektrim digunakan untuk daerah lain hanya dengan konversi selisih waktu berpedoman pada selisih nilai Bujur tempat saja, tetapi harus memperhatikan Lintang tempat dan Deklinasi Matahari. Selain itu, dibutuhkan kesepakatan antar umat Muslim pada daerah deket kutub dalam menjadikan interpolasi waktu sebagai solusi ketika terjadinya continuous twilight karena akan terasa aneh ketika seorang Muslim melaksanakan salat Isya sedangkan cahaya Matahari senja masih nampak, begitu juga saat mengerjakan salat Subuh dimana seharusnya keadaan alam gelap justru cahaya Matahari masih nampak dan harus rela berhenti makan dan minum untuk memulai puasa 
AL-MARSHAD: JURNAL ASTRONOMI ISLAM DAN ILMU-ILMU BERKAITAN

ISSN 2442-5729 (print) || ISSN 2598-2559 (online), http://jurnal.umsu.ac.id/index.php/almarshad DOI: https://doi.org/10.30596/jam.v4i1.1938

Published June 2018

padahal cahaya senja masih dapat dinikmati.

\section{Daftar Pustaka}

Amrullah, Moh. Afif. (2011). "Penentuan Awal Waktu Shalat Subuh Menurut Kementrian Agama dan Aliran Salafi", Jurnal Hukum dan Syariah JURISDICTIE Vol 2, No 2 Desember.

Azhari, Susiknan. (2007). Ilmu Falak (Perjumpaan Khazanah Islam dan Sains Modern). Yogyakarta: Suara Muhammadiyah, cet. II.

Departemen Agama Republik Indonesia. (2009). Al-Qur'an AlQur'an dan Terjemahnya. Jakarta: Sygma Creative Media Crop.

Djamaluddin, Thomas. (2005) Menggagas Fiqih Astronomi (Telaah Hisab-Rukyat dan Pencarian Solusi perbedaan hari Raya). Bandung:Kaki Langit, cet. I.

\begin{tabular}{crr} 
& & (2006). \\
\hline Menjelajah & Keluasan & Langit \\
Menembus & Kedalaman & $A l-$ \\
qur'an. & Lembang: Penerbit \\
Khazanah Intelektual, Cet I.
\end{tabular}

(2011).
Penyatuan Umat. Jakarta:

LAPAN.

Djambek, Sa'addoedin. (1974). Salat dan Puasa di Daerah Kutub. Jakarta: Bulan Bintang.

Jannah, Sofwan. (2007). "Urgensi Hisab dan Rukyat pasca UU No. 3 Tahun 2006", Islamic University of Indonesia: AlMawarid Jurnal Hukum Islam Vol 17.

Jayusman. (2013). "Pemikiran Ilmu Falak Kyai Noor Ahmad SS". Disertasi Program Pascasarjana IAIN Walisongo Semarang: Perpustakaan Walisongo.

Kementerian Agama. (2010). Almanak Hisab Rukyat. Jakarta: Kementrian Agama.

Khoiri, Ahmad. (2017). "Penentuan Awal Waktu Shalat Fardhu dengan Peredaran Matahari", JURNAL SPEKTRA Vol 3, No 1: Kajian Sains, Sains Terapan.

Sayyid Sabiq. (1990). Fiqhus Sunnah. Jilid I, Mesir: Darul Fatah li I'lam Arabi.

Ash-Shiddieqy, T.M. Hasbi. (1954). Pedoman Puasa. Jakarta: Bulan Bintang.

Asronomi Memberi Solusi 
Asy-Syafi'i, Al-Imam Yahya bin Syarif an-Nawawi ad-Dimsyiqy, tt., Shahih Muslim bi Syarhi anNawawi, Jus 17, Beirut; Dar alDekat kutub al-`Alamiyyah.

Syaltout, Mahmud. (1972). FatwaFatwa. Jilid I, Terj. Fatawa. Jakarta: Bulan Bintang.

Syihab, H.Z.A. (1995). Tuntunan Puasa Praktis. Jakarta : Bumi Aksara.

Az-Zuhaili, Wahbah. (2006). Fiqih Islam Wa Adillatuhu. Damaskus: Dar al-Fikr. Juz 2.

https://tdjamaluddin.wordpress.com/ diakses pada tanggal 29 Mei 2017 jam 13:20 WIB.

https://tdjamaluddin.wordpress.com/1-

t-djamaluddin-

thomas\%20djamaluddin/ diakses pada tanggal 29 Mei 2017 jam 12:54 WIB. 